\title{
A Survey on Pattern of Ocular Morbidity in a Rural Community in Rwanda
}

\author{
Kingsley Ekemiri*, Lilian Omondi, Marie Josee Uwisunze, Francois Regis Twiringirimana, \\ Denys Ndayambaje, Fiston Kitema
}

Department of Ophthalmology, College of Medicine and Health Sciences, University of Rwanda, Kigali, Rwanda

Email: *doctorkingsley1981@gmail.com

How to cite this paper: Ekemiri, K., Omondi, L., Uwisunze, M.J., Twiringirimana, F.R., Ndayambaje, D. and Kitema, F. (2019) A Survey on Pattern of Ocular Morbidity in a Rural Community in Rwanda. Open Journal of Ophthalmology, 9, 54-63. https://doi.org/10.4236/ojoph.2019.92007

Received: December 29, 2018

Accepted: March 23, 2019

Published: March 26, 2019

Copyright $\odot 2019$ by author(s) and Scientific Research Publishing Inc. This work is licensed under the Creative Commons Attribution International License (CC BY 4.0).

http://creativecommons.org/licenses/by/4.0/

\begin{abstract}
Background: Majority of ocular morbidities found in developing countries are preventable and curable and vary from country to country and from community to community. Screening of ophthalmic conditions in communities with underserved ophthalmic services, can help detect and treat various spectra of ocular morbidity. Untreated ocular conditions may lead to vision impairments and blindness. Methods: A free walked-in ophthalmic screening outreach survey was conducted at a rural community in Rwanda and the total number of attendees was 762. Patients' demographics, detailed case history, and ophthalmic specific evaluation tests generated the survey data. Treatment offered was based on the diagnoses made. Patients who required special treatment or reviews were referred to the health care facilities for further investigations and subsequent management. The recorded data on observation forms were analyzed by Statistical Package for Social Sciences (SPSS) computer software using descriptive statistics. Results: Majority (91.5\%) of the patients were from Mageragera community where the outreach was conducted. The number of females $71.7 \%$ (546) seen were more than males $28.3 \%$ (213) in the ratio of 2.5:1. Age group with the highest number of patients was $(1-10)$ years, $139(18.2 \%)$ while the least was $\geq 71$ years, $34(4.5 \%)$. Among ocular morbidities diagnosed, conjunctivitis ranked highest 562 (73.8\%), followed by refractive errors $118(15.5 \%)$ and cataract $31(4.1 \%)$. Glaucoma was diagnosed in $4(0.5 \%)$ clients. Medication given included steroidal, non-steroidal and antibiotics ophthalmic drugs. Conclusion: A total of 762 patients benefited from early diagnoses, treatment and referrals. The pattern of eye diseases observed was similar to other reports from other developing countries. Statistics from this survey provides baseline data which can be used for planning, management and prevention of ocular conditions in the studied community as well as in research.
\end{abstract}




\section{Keywords}

Ocular Morbidity, Patterns, Rural Community, Screening

\section{Introduction}

Most ocular morbidities found in developing countries are preventable and curable but faced with inadequate availability of ophthalmic services in the rural communities [1]. This implies that eye health services are not readily accessible to majority of the population in the rural areas. Undetected and untreated ocular morbidities increase vulnerability to blindness [2]. "Ocular Morbidity" is best described as the spectrum of eye disease or disorder experienced by a population or community [1].

Rwanda as a developing country still struggles with equality in provision of healthcare including eye care services. Researchers have documented that free eye screening program as an intervention strategy is very useful to detect, treat and prevent blindness and visual impairment in the target community. Such intervention can help ascertain the pattern of ocular morbidity present in a given community population for better planning.

\section{Background}

World Health Organization (WHO) made an estimate in 2010, that there were 285 million people visually impaired of which 39 million are totally blind, $80 \%$ of which are preventable and curable [3]. In Africa the number of visually impaired is estimated to be 26 million out of which 6 million are blind; this estimate was derived from a population based study in Botswana, Cameroon, Eritrea, Ethiopia, Gambia, Ghana, Kenya, Mali, Nigeria, Rwanda, Uganda and Tanzania [2].

The pattern of ocular disease varies from country to country and even in the same country from district to district [4]. The two main causes of visual impairment in the world are uncorrected refractive error (42\%) and cataract (33\%), [1]. A study conducted in Asia in Western Nepal, indicates that refractive error $(26.8 \%)$ is the most common ocular morbidity followed by conjunctivitis (20.6\%), cataract (11.8\%), and pterygium (6\%), [5].

In a rural community in Ethiopia, four ocular morbidities were identified in order of severity included conjunctivitis (29\%), cataract (16.3\%), presbyopia (15.4\%) and uncorrected refractive error (7.9\%), [6]. In Imo State, Nigeria rural communities were screened, and the most common ocular morbidities found were refractive error (31.6\%), glaucoma (23.5\%), presbyopia (17\%) and cataract (12\%), which were suggestive of establishing well equipped primary eye care services [7].

Rwanda is a sovereign state in East Africa with a widely varied geography [8] (Figure 1). It has one of the highest population densities in Africa (1060/sq.mi) with majority of them living in the rural areas (Figure 2). In 2018, the population was estimated to increase from 11.8 million in 2013 to 12.50 million [8]. The 


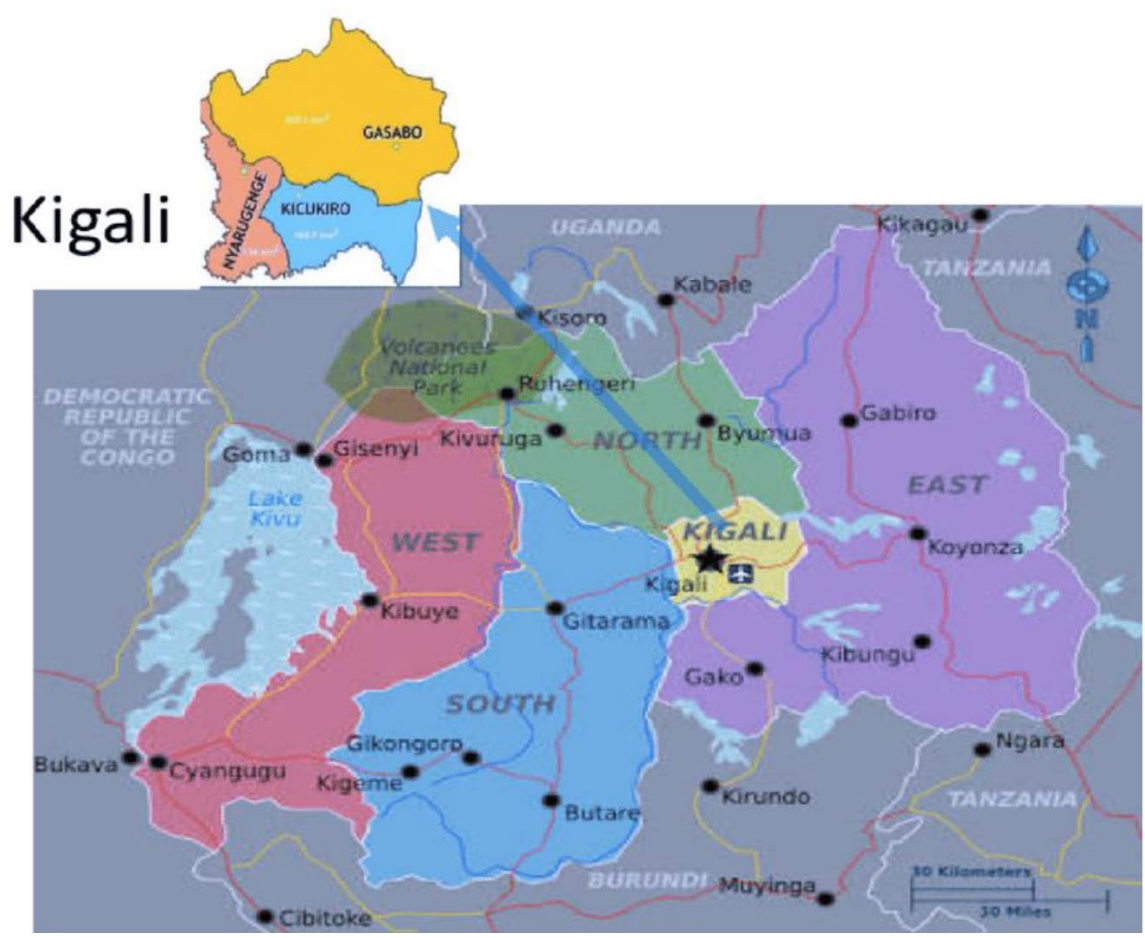

Figure 1. Map of Rwanda (Yellow).

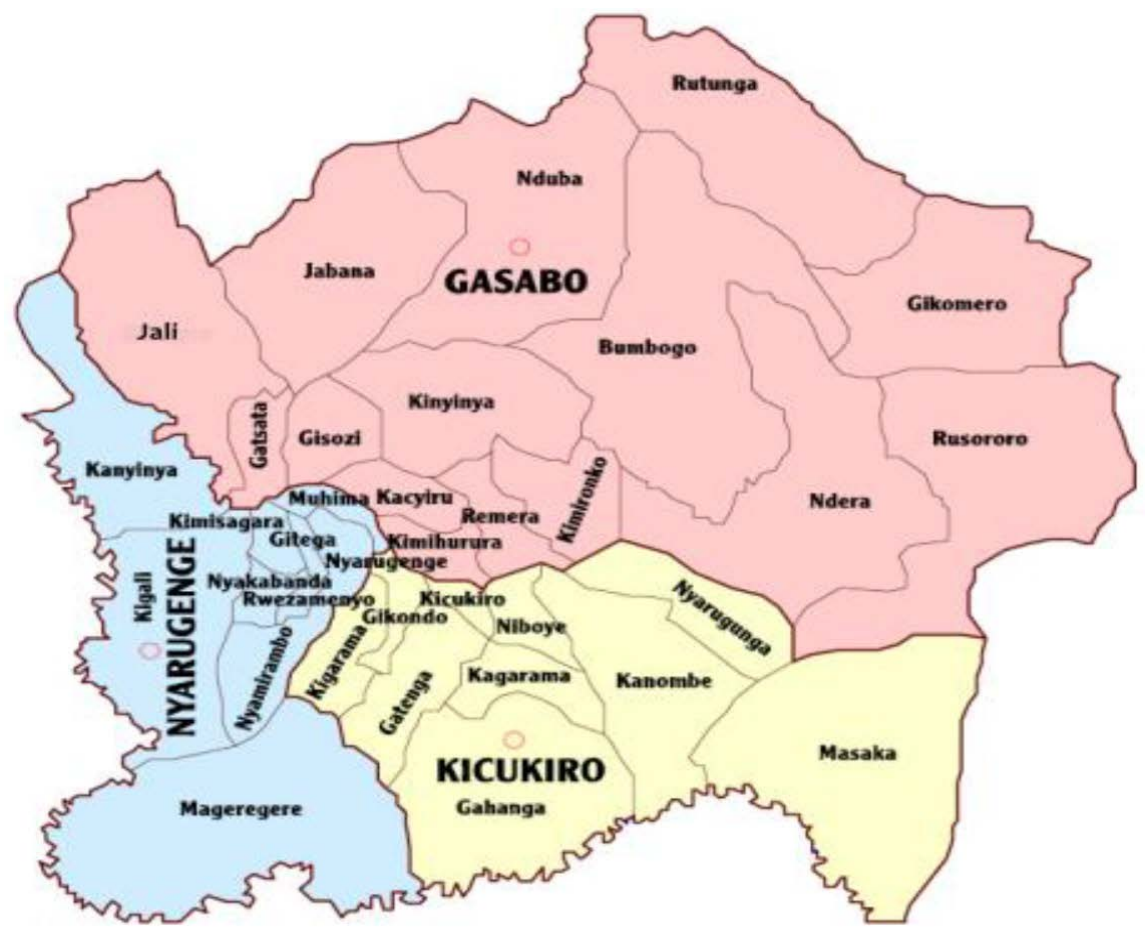

Figure 2. Mageragera sector (Blue).

overall prevalence of visual impairment in Rwanda was 5.3\% in 2006 (not including presbyopia) and the prevalence of blindness was $1.8 \%$ [9].

This survey was undertaken and designed to determine the pattern of ocular diseases and disorders in a rural community in Rwanda, to determine the ocular 
morbidity prevalence and to determine the gender and age of those with these ocular morbidities. The information obtained herewith, will assist to facilitate planning of important primary eye care systems that will be put in place via a viable policy for monitoring of epidemiological trends that causes visual impairment which may change from time to time.

\section{Subjects and Methods}

\subsection{Study Area}

The free medical visual outreach was conducted on $18^{\text {th }}-21^{\text {st }}$ May, 2015 at Mageragere sector, Nyarugenge District, Kigali province, Rwanda (Figure 1). Mageragere Community (Figure 2) has an estimated population size of 23,407, an area size of $54.7 \mathrm{~km}^{2}$ and a density of $428.3 / \mathrm{km}^{2}$ [8].

\subsection{Study Design}

This was a cross sectional study of self-directed walk in patients that were interested in participating during the free medical visual outreach organized by the University of Rwanda, College of Medicine and Health Sciences (UR-CMHS).

Kigali. The district mayor and sector leader was informed through the protocol channels prior to the outreach to give an update about the purpose of the outreach \& seek permission to enter the Mageragere community. The location and date for the outreach was also approved. The community also saw the benefit of this program on their ocular health and assurance was given, that they will not be expose to any harm, the screening was conducted for three days, subsequently a total of 762 patients registered, making up the sample size. Data was solicited from the oral interviews to obtain detailed case history, and participant evaluation using observation forms.

All patients had their vision tested with the Snellen's chart for those who are literate, otherwise a tumbling E chat was used also for those who are illiterate and the best smallest line which the participant can read was recorded as the visual acuity (VA). Those that could not read the biggest letters (6/60) in both charts due to very poor vision were ask to count finger (CF) at less than 6meters. Those who were not able to count the fingers due to poor vision were retested for perception of light (PL) with the penlight at $33 \mathrm{~cm}$. Pinhole test was used for those with poor vision $(<6 / 18)$, where necessary, the optometrist performed either dry or wet retinoscope or subjective refraction where applicable. The anterior segment was examined with pentourch and a loupe where applicable, the fundus of the patient eye was dilated where applicable to enhance visibility of the fundus and the posterior segment when examined with keeler ophthalmoscopy, dilated fundus examination was performed when necessary. Cases that require more detailed examination were reassessed using the Slit lamp biomicroscope and were referred to the nearest secondary or tertiary eye unit putting into consideration the participant home address.

The WHO recommended categories were referred, to objectively state when a 
vision is normal, impaired or blinded. Visual acuity equal to or better than $6 / 18$ was considered as a normal central vision and when worse than $6 / 18$ as moderate to severe visual impairment. Glaucoma with the intraocular pressure (IOP) of more than $25 \mathrm{mmHg}$ and a cup-to-disc ration of 0.7 to 1.0 or an IOP of about $35 \mathrm{mmHg}$ with a fixed dilated pupil, but participants with ocular hypertension IOP between 20 to $35 \mathrm{mmHg}$ and no glaucomatous cupping was regarded as ocular hypertension. The diagnosis was made based on the case history for each participant, clinical findings, records for age, sex, VA and ocular morbidity was recorded. Data collected was coded and fed into SPSS (Statistical Package for Social Sciences) version 20.0 for statistical analysis.

\subsection{Selection Criteria}

\subsubsection{Inclusion Criteria}

All patients aged lyear and above that registered, for the children the assent forms must be signed by the parents or guardian before the registration for participating in the outreach.

\subsubsection{Exclusion Criteria}

All client who did not register for the free medical visual outreach was not part of the study.

\subsection{Data Management}

The data collected was well secured and kept highly confidential by the researcher locked in the computer with a special password, the data were analyzed using Comparison of variables was carried out using appropriate statistical tests by SPSS 21 version.

\subsection{Ethical Consideration}

The study was approved by the Institutional Review Board of the University of Rwanda, College of Medicine and Health Sciences Ethics committee.

\section{Results}

A total of 762 patients were examined at Mageragere sector, the outreach location where the survey was conducted by the research team, all age group of patients were examined ranging from 1 year to 80 years. A good number (18.2\%) of them were in the age group $1-10$ years and the least were $\geq 71$ years $(4.5 \%)$ (Figure 3). Majority (91.5\%) of the respondent resides within the Mageragere community.

\section{Discussion}

During the community outreach clinic, the large turnout was seen due to the fact that the services rendered were accessible i.e. free of charge and the services were brought to the community. Demographic characteristics showed there were more females $546(71.7 \%)$ who participated than the males $213(28 \%)$ with a 


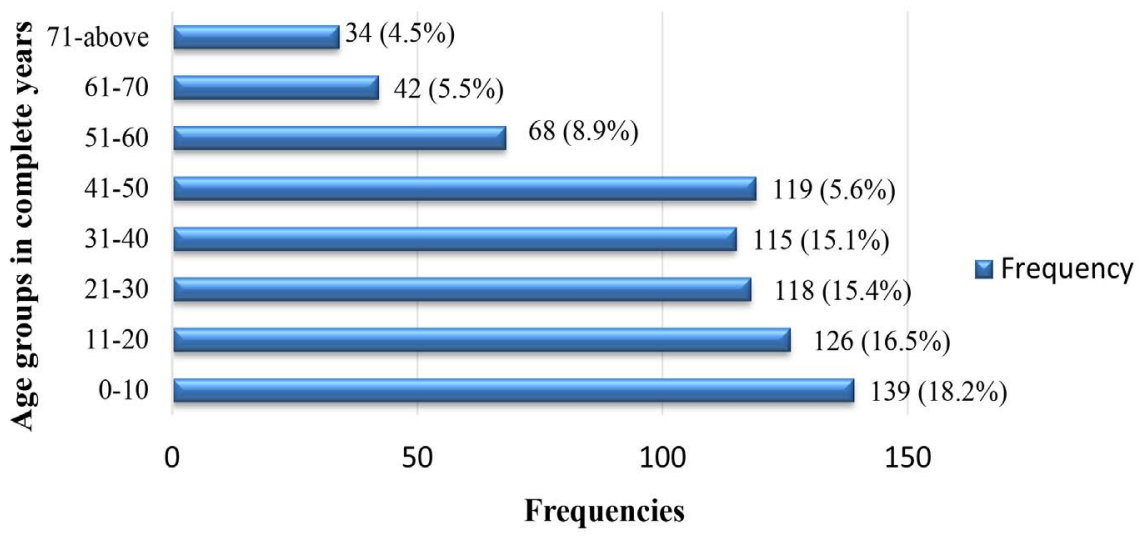

Figure 3. Age distribution of the community outreach clients, the age $0-10$ years (18.2\%) were the most active participant.

ratio of 2.5:1, these findings are similar to other studies in Nigeria and Nepal [5] [7]. Elsewhere, a study reported male preponderance and another showed equal accessibility of both gender [10] [11]. Patients examined were from all age group with the maximum numbers in the age group $1-10$ years (18\%), subsequently followed by 11 - 20 years (16\%), 41 - 50 years (15.6\%) (Figure 3). These findings are similar to a study done in India and Nigeria that showed that children are affected with ocular morbidity conditions than the older age [12] [13].

Data on patients' visual acuity showed that the unaided visual acuity of $6 / 18$ or better in at least one eye was found in 710 (92.9\%) cases, at least $20(2.6 \%)$ participants had uncorrected visual acuity of less than $6 / 60$ in the better eye (Figure 4 \& Figure 5). The undetermined cases where vision that could not be tested in about nine cases of children that was not cooperating. The visual acuity findings in this survey is far much less compared to a study done in Ethiopia were uncorrected refractive error was found to be $7.9 \%$, [6].

Table 1 shows distribution pattern of the various ocular diseases. These diseases were classified based on major complains from the clients which included itchy eyes (31\%), red eyes (20\%) and difficulty to read near prints (12\%). Adnexia conditions seen included blepharitis $4(0.5 \%)$. Conditions of the anterior segment seen included, conjunctivitis, pterygium, uveitis, dry eye, trauma and corneal abnormalities. One client had pseudoaphakia in one eye meaning the lens was removed surgically and replaced with intraocular lens while another had foreign body in one eye. Posterior segment conditions seen included, maculopathy, and hypertensive retinopathy and glaucoma.

Conjunctivitis occurred most commonly in 562 (73\%) participants, followed by refractive errors $118(15 \%)$ and 31 (4\%) cataracts. These findings are similar to a study conducted in Ethiopia, the most common of which was conjunctivitis, but the percentage was much lower (29\%), [6]. A similar study in West Nepal showed that refractive errors (26.8\%) were the most common ocular morbidity followed by conjunctivitis (20.6\%) [5]. Glaucoma was seen in 4 (0.5\%) participants classified as one of the least common causes of morbidity, contrary to 


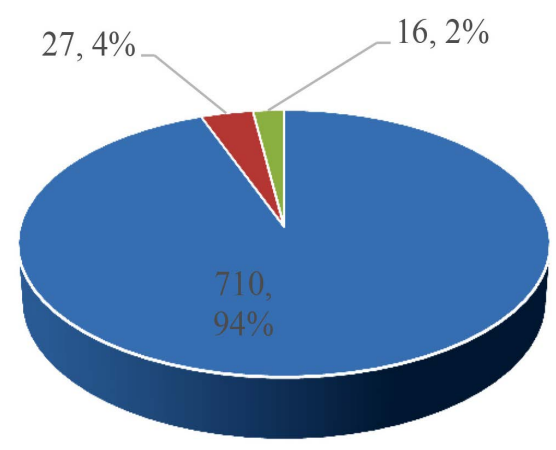

- $6 / 6-6 / 18 \quad$ - $<6 / 18-6 / 60 \quad-<6 / 60-3 / 60$

Figure 4. Visual acuity right eye.

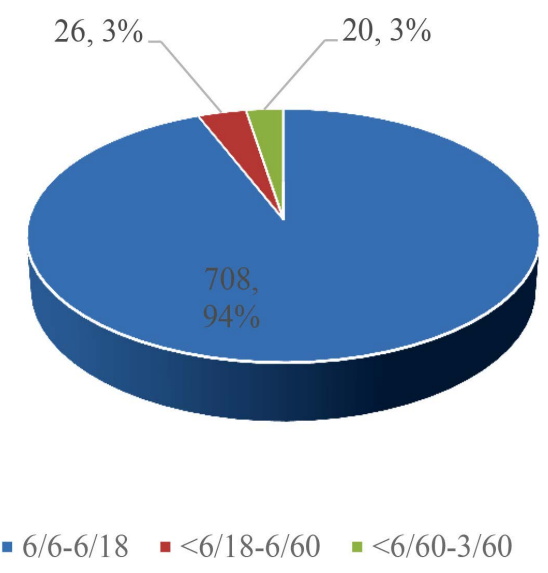

Figure 5. Visual acuity left eye.

Table 1. Pattern of ocular morbidity at a rural community in Rwanda.

\begin{tabular}{|c|c|c|c|c|c|c|c|c|c|c|c|c|c|c|}
\hline 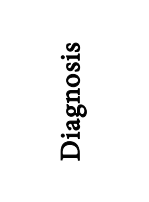 & 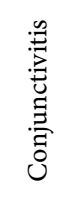 & 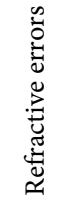 & 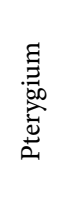 & $\begin{array}{l}\stackrel{0}{0} \\
\overrightarrow{5}\end{array}$ & 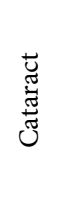 & $\begin{array}{l}\text { 节 } \\
\text { 峦 }\end{array}$ & 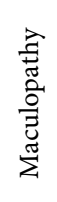 & 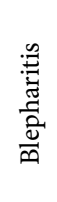 & 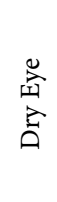 & 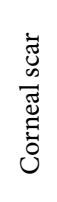 & $\begin{array}{l}\dot{\Xi} \\
\tilde{U} \\
\vec{\Xi} \\
\tilde{\Xi} \\
\dot{0}\end{array}$ & 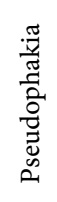 & 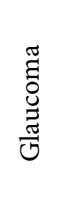 & 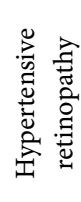 \\
\hline Frequency & 562 & 118 & 6 & 2 & 31 & 5 & 4 & 4 & 2 & 1 & 1 & 1 & 4 & 1 \\
\hline Percentage & 74.8 & 15.5 & 0.8 & 0.3 & 4.1 & 0.7 & 0.5 & 0.5 & 0.2 & 0.1 & 0.1 & 0.1 & 0.5 & 0.5 \\
\hline
\end{tabular}

findings in studies that showed that it was among the most prevalent ocular morbidities in and the most important cause of blindness in Nigeria [14] [15]. These variations in ocular morbidity patterns support that the patterns differ with countries and regions [4]. The RAAB conducted in the western province of Rwanda shows that the prevalence of bilateral blindness is $1.8 \%$, with cataracts (65\%) being the most ocular morbidity contributing to blindness, the ocular morbidity pattern in the Mageragere community differs from that in the western province of Rwanda, where cataracts were the main ocular morbidity [9]. The 
difference is related to the population of the study in which the latter studied an age group of 50 years and above. During the outreach, Figure 6 shows that corticosteroids (40\%), non-corticosteroids (21\%) and spectacles (15\%) were the main forms of treatment and management used for the subjects, the least was the removal of foreign bodies and anti-glaucoma drugs were $0.1 \%$ and $0.3 \%$ respectively (Figure 6), although in some cases it was not sufficient to eliminate the problem at once but helped to mitigate the problem [16].

\section{Limitation of the Study}

The limitations of this survey is self-directed walk in clients who thought to have some kind of eye problems subjected themselves to the screening and those who have eye problems but do not cause them pain, discomfort, redness and impairment may ignore the screening, this creates a bias of self-selection and may affect the true prevalence of ocular morbidity within the community.

\section{Conclusion}

In conclusion, we can see that there are enormous variations in different findings in different parts of the world, which shows clearly that the pattern of eye morbidity, which also results in visual impairment and blindness, varies from country to country, from community to community due to the availability of eye services, awareness of eye diseases among the community and it is therefore essential that a survey be carried out before planning for eye care in a geographical location to determine the pattern of ocular morbidity present in the population in order to effectively address these burdens of morbidity.

\section{Recommendations}

Scaling up the primary eye care sector by innovating robust intervention to target refractive errors, cataracts and even conjunctivitis, triggering evidence-based policies for various ophthalmic services that can adequately fit in the mid-level

Medication Administered

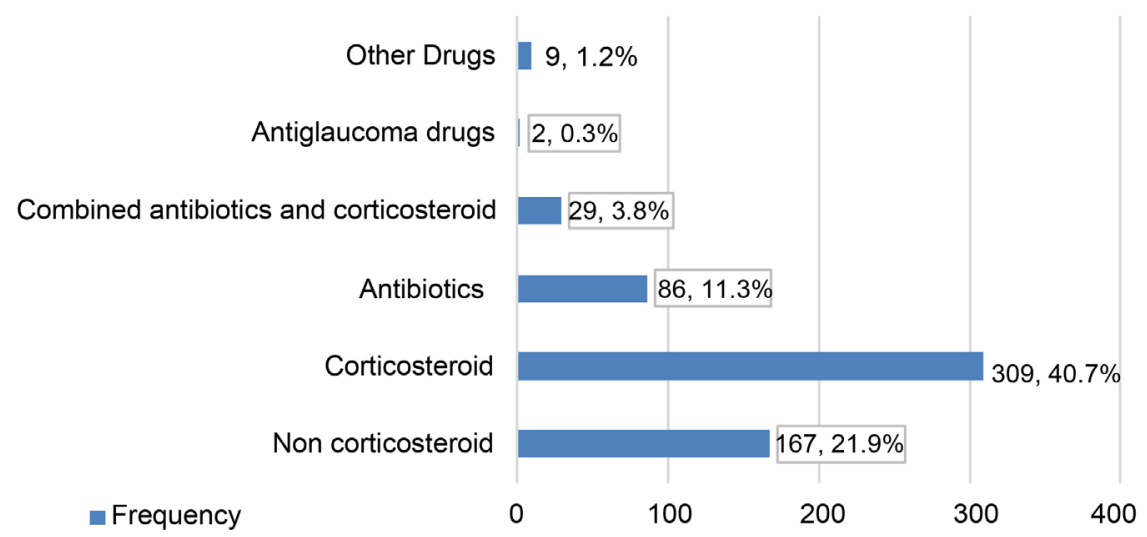

Figure 6. Medication administered for the diagnosed ocular conditions, $40 \%$ were administered corticosteroid. 
cadre of the eye care system, emphasizing on equipment to improve primary diagnosis, ensuring the continuous upgrade of the various cadres, supervision of the staff and a sound referral system that will not necessarily strain the tertiary level (Ophthalmologist), transferring of certain eye care services from the tertiary to the secondary and from the secondary to the basic primary eye unit and instilling a robust referral system will increase efficiency and improve access, trust and reduce the burden to the eye care services.

\section{Acknowledgements}

We would like to thank the authorities of Mageragere sector, Nyarugenge Province, Rwanda and all the staff of Ophthalmology Department, College of Medicine and Health Sciences, the University of Rwanda for their support in carrying out this study.

\section{Conflicts of Interest}

The authors have declared that no competing interests exist.

\section{Authors Contribution}

The study was conceived by KE, LO, DN, MU, FT, and FK and contributed to writing the paper. KE, LO, MU, and DN analyzed the data. KE and FT registered clients. KE and LO designed the study.

\section{References}

[1] Kimani, K., Lindfield, R., Senyonjo, L., Mwaniki, A. and Schmidt, E. (2013) Prevalence and Causes of Ocular Morbidity in Mbeere District, Kenya. Results of a Population-Based Survey. PloS ONE, 8, e70009. https://doi.org/10.1371/journal.pone.0070009

[2] Naidoo, K., Gichuhi, S., Basanez, M., et al. (2014) Prevalence and Causes of Vision Loss in Sub-Saharan Africa: 1990-2010. British Journal of Ophthalmology, 98, 612-618. https://doi.org/10.1136/bjophthalmol-2013-304081

[3] World Health Organization (2013) WHO Draft Action Plan for the Prevention of Avoidable Blindness and Visual Impairment 2014-2019. Universal Eye Health: A Global Action Plan 2014-2019. World Health Organization, Geneva.

[4] Abraham, E. and Megbelayin, E. (2017) Pattern of Eye Diseases among Participants of Free Eye Screening Program in Uyo, Akwa Ibom State, Nigeria. International Journal of Community Medicine and Public Health, 4, 657-661. https://doi.org/10.18203/2394-6040.ijcmph20170735

[5] Tuladhar, S., Dhakal, S. and Dhakal, S. (2013) A Pattern of Ocular Morbidity in Patients Attending Anophtalmic Clinic in a Rural Part of Western Nepal. Journal of Nobel Medical College, 2, 27-30. https://doi.org/10.3126/jonmc.v2i1.7669

[6] Addisu, Z. (2013) A Study of Ocular Morbidity of Patients Attending Ophthalmic Outreach Services in Rural Ethiopia. International Journal of Medicine and Medical Sciences, 3, 450-454.

[7] Achigbu, E.O. and Ezeanosike, E. (2017) Visual Impairment and Blindness in five Communities in IMO State, South East Nigeria. Annals of Medical and Health 
Science Research, 7, 106-110.

[8] NISR (2018) Population Size and Population Characteristics. http://www.statistics.gov.rw/statistical-publications/subject/population-size-and-po pulation-characteristics

[9] Mathenge, W., Nkurikiye, J., Limburg, H. and Kuper, H. (2007) Rapid Assessment of Avoidable Blindness in Western Rwanda: Blindness in a Post Conflict Setting. PLoS Medicine, 4, e21710. https://doi.org/10.1371/journal.pmed.0040217

[10] Rizyal, A., Shakya-Vaidya, S., Shrestha, R.K. and Shrestha, S. (2010) A Study of Ocular Morbidity of Patients Attending a Satellite Clinic in Bhaktapur, Nepal. Nepal Medical College Journal, 12. 87-89.

[11] Ukponmwan, C.U. (2013) Pattern of Ocular Morbidity in Nigeria. Asian Pacific Journal of Tropical Disease, 3, 164-166. https://doi.org/10.1016/S2222-1808(13)60064-X

[12] Rao, G.N., Sabnam, S., Pal, S., Rizwan, H., Thakur, B. and Pal, A. (2018) Prevalence of Ocular Morbidity among Children Aged 17 Years or Younger in the Eastern India. Clinical Ophthalmology (Auckland, N.Z.), 12, 1645-1652. https://doi.org/10.2147/OPTH.S171822

[13] Senyonjo, L., Lindfield, R., Mahmoud, A., Kimani, K., Sanda, S. and Schmidt, E. (2014). Ocular Morbidity and Health Seeking Behaviour in Kwara State, Nigeria: Implications for Delivery of Eye Care Services. PloS ONE, 9, e104128. https://doi.org/10.1371/journal.pone.0104128

[14] Wokoma, F.S. and Ichenwo, T. (2011) Pattern of Eye Disorders in Ogbodo: A Rural Community in Rivers State. Nigerian Health Journal, 11, 14-18.

[15] Monsudi, K.F., Saka, E.S. and Azonobi, R.I. (2015) Pattern of Eye Diseases Presents at Free Outreach in Rural Community in the Northwestern Nigeria. Sudan Medical Monitor, 10, 113-116. http://www.sudanmedicalmonitor.org/text.asp?2015/10/4/113/171862

[16] Tsai, T., Robin, A.L. and Smith, J.P. (2007) An Evaluation of How Glaucoma Patients Use Topical Medications: A Pilot Study. Transactions of the American Ophthalmological Society, 105, 29-35. 